\title{
Effect of Si on DC arc plasma generation from Al-Cr and Al-Cr-Si cathodes used in oxygen
}

Igor Zhirkov, Ludvig Landälv, E. Gothelid, M. Ahlgren, Per Eklund and Johanna Rosén

\author{
Journal Article
}

\section{Tweet}

N.B.: When citing this work, cite the original article.

Original Publication:

Igor Zhirkov, Ludvig Landälv, E. Gothelid, M. Ahlgren, Per Eklund and Johanna Rosén, Effect of Si on DC arc plasma generation from Al-Cr and Al-Cr-Si cathodes used in oxygen, Journal of Applied Physics, 2017. 121(8), pp..

http://dx.doi.org/10.1063/1.4976862

Copyright: AIP Publishing http://www.aip.org/

Postprint available at: Linköping University Electronic Press

http://urn.kb.se/resolve?urn=urn:nbn:se:liu:diva-136304

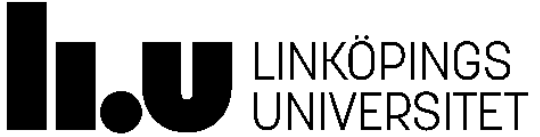




\title{
Effect of Si on DC arc plasma generation from $\mathrm{Al}-\mathrm{Cr}$ and $\mathrm{Al}-\mathrm{Cr}-\mathrm{Si}$ cathodes used in
} oxygen

\author{
I. Zhirkov, ${ }^{1, a}$ L. Landälv, ${ }^{1,2}$ E. Göthelid, ${ }^{2}$ M. Ahlgren, ${ }^{2}$ P. Eklund, ${ }^{1}$ and J. Rosen ${ }^{1}$ \\ 1 Thin Film Physics Division, Department of Physics, Chemistry and Biology (IFM), \\ Linköping University, SE-581 83 Linköping, Sweden \\ ${ }^{2}$ Sandvik Coromant AB, Stockholm SE-12680, Sweden
}

\begin{abstract}
$\mathrm{Al}_{2} \mathrm{O}_{3}$ alloyed with $\mathrm{Cr}$ is an important material for the tooling industry. It can be synthesized from an arc discharge using Al-Cr cathodes in an oxygen atmosphere. Due to formation of Al-rich oxide islands on the cathode surface, the arc process stability is highly sensitive to the oxygen pressure. For improved stability, the use of $\mathrm{Al}_{0.70} \mathrm{Cr}_{0.25} \mathrm{Si}_{0.05}$ cathodes has previously been suggested, where Si may reduce island formation. Here, we have investigated the effect of Si by comparing plasma generation and thin film deposition from $\mathrm{Al}_{0.7} \mathrm{Cr}_{0.3}$ and $\mathrm{Al}_{0.7} \mathrm{Cr}_{0.25} \mathrm{Si}_{0.05}$ cathodes. Plasma ion composition, ion energies, ion charge states, neutral species, droplet formation and film composition have been characterized at different $\mathrm{O}_{2}$ flow rate for arc currents of 60 and $90 \mathrm{~A}$. Si and related compounds are detected in plasma ions and in plasma neutrals. Scanning electron microscopy and energy dispersive X-ray analysis show that the cathode composition and the film composition are the same, with Si present in droplets as well. The effect of Si on the process stability, ion energies, and ion charge states is found to be negligible compared to that of the arc current. The latter is identified as the most relevant parameter for tuning the properties of the reactive discharge. The present work increases the fundamental
\end{abstract}

\footnotetext{
a Corresponding author: igozh@ifm.liu.se, phone +46 7305210 12, fax +46 13137568
} 
understanding of plasma generation in a reactive atmosphere, and provides input for the choice of cathode composition and process parameters in reactive DC arc synthesis.

\section{INTRODUCTION}

The reactive DC arc discharge is an extensively used process for deposition of coatings of complex materials such as oxides, nitrides or carbides. ${ }^{1}$ The deposited materials have immense range of applications, such as protective, wear-resistant or decorative layers for automotive, space or medical industries to cite a few.

For many decades, aluminum oxide coatings (different $\mathrm{Al}_{2} \mathrm{O}_{3}$-polymorphs) used as wear resistant layer on cuttings tools were mainly limited to being deposited by chemical vapor deposition (CVD). ${ }^{2-4}$ The thermodynamically stable corundum $(\alpha)$-phase has been of primary interest, and the latest increase in tool life performance from $\alpha-\mathrm{Al}_{2} \mathrm{O}_{3}$ coatings, comes from the introduction of highly (0001) textured $\alpha-\mathrm{Al}_{2} \mathrm{O}_{3} .{ }^{5,6}$ These CVD coatings are, however, limited by their inherent problem of cracking upon cooling due to differences in thermal expansion between coating and substrate and the tensile stresses formed in the film. ${ }^{6}$

To address these challenges, physical vapor deposition (PVD) techniques, such as DC $\operatorname{arc}^{7-9}$ pulsed DC $\operatorname{arc}^{10}$ and different types of sputtering techniques ${ }^{11-17}$ have been used at lower deposition temperatures than CVD. These techniques allow operation far from thermodynamic equilibrium, and tailoring of the compressive stress levels in the coating by ion bombardment. At the lower deposition temperatures employed in PVD, other $\mathrm{Al}_{2} \mathrm{O}_{3}$ phases are often obtained, primary $\gamma-\mathrm{Al}_{2} \mathrm{O}_{3}$. However, even when $\alpha-\mathrm{Al}_{2} \mathrm{O}_{3}$ can be achieved, challenges such as difficulties to implement magnetic filters combined with oxygen flow outlet in batch coaters, ${ }^{11}$ coating porosity, and difficulties to scale current densities, ${ }^{12,13}$ have hindered large scale industrial use of these coatings within the cutting tool business.

In order to stabilize the corundum phase with PVD, different approaches have been used, such as crystallographic seed layer ${ }^{18-21}$ or a solid solution with an element which 
promotes the corundum phase even at low temperatures $\left(\sim 500{ }^{\circ} \mathrm{C}\right) .{ }^{22-26} \mathrm{Cr}$, forming $\mathrm{Cr}_{2} \mathrm{O}_{3}$, is the most promising element for this purpose and presently used industrially, ${ }^{22,}{ }^{27}$ while also $\mathrm{Cu}$ and $\mathrm{Fe}$ are under investigation. ${ }^{23,} 24,28$ Furthermore, depositing AlCrO results in some cases in a relatively recently discovered cubic B1-like defect stabilized phase. ${ }^{29-32}$

Based on this background, arcing from Al-Cr containing cathodes in an oxygen atmosphere is of high technological importance. However, the process can result in formation of Al-rich oxide islands on the cathode surface, and formation of metallic droplets in the coating, ${ }^{10,22,33,34}$ which may limit the cathode utilization, and influence the coating properties. However, for an isotropic plasma expansion, the average coating composition matches the virgin cathode composition even when having oxide islands on the cathode. ${ }^{34,35}$

Cathode contaminations in reactive arc processes typically include three main phenomena: 1) A change in melting point and cohesive energy of the contaminated surface layer. This may lead to altered properties of the material flux from the cathode. ${ }^{1,36-38} 2$ ) Contaminations, which may lead to differences in electrical conductivity. ${ }^{38}$ At the cathode this may lead to changed arc behavior, and dissociation of the arc spot into several simultaneous emission centers affecting the material flux. ${ }^{1,38-41}$ This dissociation is more prone to take place for insulating layers than for conducting ones such as $\mathrm{TiN}^{38} 3$ ) Localization of the arc movement due to completely electrically isolating regions, such as $\mathrm{Al}_{2} \mathrm{O}_{3}$, on the cathode surface which may cause instability of the arc. ${ }^{33}$ Oxide formation can also take place at the substrate and the anode (chamber wall and/or separate anode), in turn influencing the stability of the arc. However, effects from such oxidation of is scarcely studied for DC arc processes.

Based on these three contaminations effects it is clear that the degree of contamination of the cathode will heavily influence the arc process. The contaminated area is determined by a ratio between formation and erosion rate of the contaminations. The erosion rate is 
correlated to the arc current and the intensity of the material flux from the cathode, ${ }^{1}$ while the formation rate is correlated to the pressure of the reactive gas. ${ }^{42}$ Furthermore, the operational pressure determines the plasma - gas interaction during plasma transport, ${ }^{43}$ and therefore, the pressure controls the nature and rate of the species arriving at the substrate, forming the coating.

To improve the stability of the deposition process of $\left(\mathrm{Al}_{0.7} \mathrm{Cr}_{0.3}\right)_{2} \mathrm{O}_{3}$ coatings, addition of 5 at\% Si in the cathode was recently suggested. ${ }^{44}$ Si was assumed to reduce/prevent the formation of $\mathrm{Al}_{2} \mathrm{O}_{3}$ oxide islands on the cathode surface. Furthermore, no $\mathrm{Si}$ was detected in the coatings, which was proposed to be due to the formation of volatile $\mathrm{SiO}_{\mathrm{x}}$ species. ${ }^{44}$ However, preliminary results ${ }^{45}$ show that all coatings made in the same type of deposition system, using various $(\mathrm{Al}, \mathrm{Cr}, \mathrm{Si})$ cathodes and $\mathrm{O}_{2}$-flow, contained silicon, thus not corroborating the results of Ref. 44. Therefore, there is a need to understand the three material fluxes (ions, neutrals, and droplets) present during the deposition. The plasma characteristics for the $\mathrm{Al}_{0.7} \mathrm{Cr}_{0.25} \mathrm{Si}_{0.05}$ cathode have, however, not been previously studied.

In the present study, we have performed plasma characterization of an unfiltered reactive DC arc discharge. The effect of cathode composition, $\mathrm{Al}_{0.7} \mathrm{Cr}_{(0.3-\mathrm{x})} \mathrm{Si}_{\mathrm{x}}$ ( $\mathrm{x}=0$ and 0.05), arc current, and $\mathrm{O}_{2}$ flow rate on plasma chemistry, ion energy, droplet generation, and film composition has been studied with the aim of clarifying general and fundamental features of the reactive arc discharge, and in particular the effect of Si in the AlCr-cathode.

\section{EXPERIMENTAL DETAILS}

\subsection{Plasma analysis}

The experiments were performed using a deposition system equipped with an industrial scale DC arc source (Ionbond) for $63 \mathrm{~mm}$ diameter cathodes. $\mathrm{Al}_{0.7} \mathrm{Cr}_{0.3}$ and $\mathrm{Al}_{0.7} \mathrm{Cr}_{0.25} \mathrm{Si}_{0.05}$ cathodes were used as produced by powder metallurgy. ${ }^{46,47}$ The arc source was operated 
with an arc current of 60 and $90 \mathrm{~A}$, and the base pressure of the system was around $5 \times 10^{-}$ ${ }^{4} \mathrm{~Pa}$. No external magnetic field was used. A mass-energy-analyzer (MEA, Hiden Analytics model EQP) was positioned in front of the arc source with the orifice (50 $\mu$ m diameter) about $33 \mathrm{~cm}$ from the cathode surface. For each cathode, the plasma was characterized through mass-scans at fixed ion energy and energy-scans at fixed mass-to-charge ratio for all detected ions. The energy scans were recorded in steps of $0.25 \mathrm{eV} /$ charge up to $200 \mathrm{eV} /$ charge to capture the entire ion energy distribution (IED). The presence of isotopes in the ion flux and their influence on relative ratios of the measured IEDs were evaluated according to previous work. ${ }^{48}$ Measured distributions were recorded at least three times to ensure consistency of the data. The measured raw data are given as energy per charge. For multiple charged ions, the energy scale was therefore multiplied by the ion charge-state to display the "true" energy distribution function. ${ }^{49}$ Furthermore, the measured intensity has been divided by the ion charge state, to compensate for the charge-state dependence of the analyzer's transmission window. ${ }^{49,50}$ Over time the MEA orifice may be coated and the recorded intensity reduced as an effect of reduced orifice size. To prevent this effect, the inlet channel was cleaned after finalized analysis from each cathode. Using the "neutral mode" of the mass-energy analyzer, ${ }^{51}$ the absolute intensity of neutral species was also recorded. The average ion energies and the ratios between total intensities of IEDs of different ions in one cathode were found to be reproducible within 5-7\%. All other parameters studied here, such as pressure in the chamber and electrical potential at the cathode, were found to be within 5\% reproducibility.

To achieve steady state conditions for arc operation, the temporal evolution of the working pressure, the potential at the cathode, and IEDs have been studied. It was found that after 4-5 minutes from arc ignition, changes in the parameters and in the IEDs become 
insignificant. Hence, all here presented data have been collected after 10 minutes of arc operation.

\subsection{Deposition and characterization of coatings}

Films were deposited from the $\mathrm{Al}_{0.7} \mathrm{Cr}_{0.3}$ and $\mathrm{Al}_{0.7} \mathrm{Cr}_{0.25} \mathrm{Si}_{0.05}$ cathodes on grounded MgO substrates in a position equivalent to the front end of the plasma analyzer. No sample rotation, additional heating or biasing was applied. Temperature calibrations showed a substrate temperature not exceeding $250{ }^{\circ} \mathrm{C}$ for a deposition time of $20 \mathrm{~min}$. Compositions and thickness of the films were characterized using a LEO 1550 scanning electron microscope (SEM) equipped with energy dispersive X-ray spectroscopy (EDS).

\section{RESULTS AND DISCUSSION}

\subsection{Process parameters in the steady state regime}

Figure 1 shows the pressure and the cathode potential with respect to ground as functions of the $\mathrm{O}_{2}$ inflow rate for $\mathrm{Al}_{0.70} \mathrm{Cr}_{0.30}$ and $\mathrm{Al}_{0.70} \mathrm{Cr}_{0.25} \mathrm{Si}_{0.05}$ cathodes used at arc currents of 60 and $90 \mathrm{~A}$.

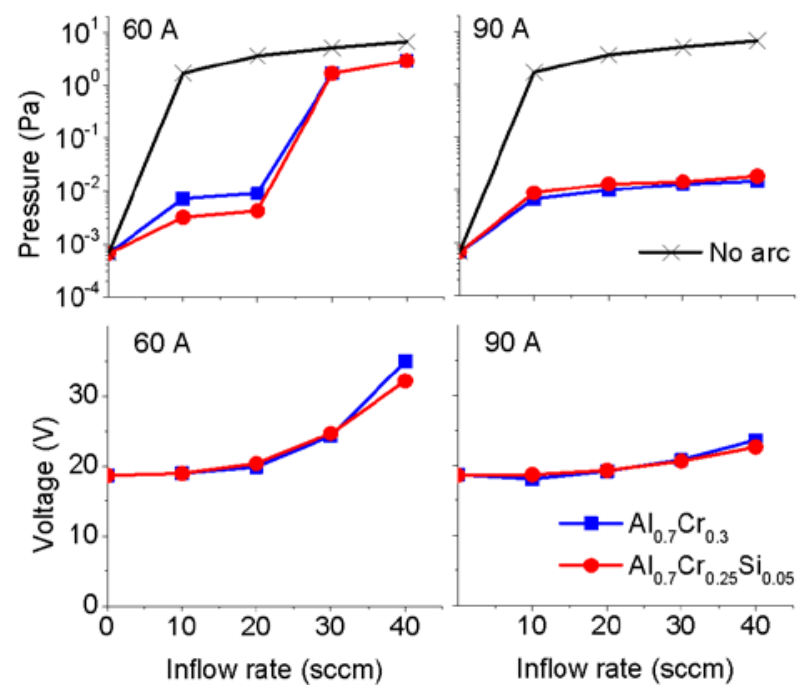


Figure 1 Pressure in the chamber (top) and potential at the cathode (bottom) as function of flow rate of $\mathrm{O}_{2}$ in plasma from $\mathrm{Al}_{0.70} \mathrm{Cr}_{0.30}$ and $\mathrm{Al}_{0.70} \mathrm{Cr}_{0.25} \mathrm{Si}_{0.05}$ cathodes used at an arc current of $60 \mathrm{~A}$ (left) and $90 \mathrm{~A}$ (right).

As shown in Fig. 1, the discrepancies between the pressure and voltage curves for the different cathode compositions are much less pronounced than the difference between the curves measured for $60 \mathrm{~A}$ and $90 \mathrm{~A}$. Furthermore, for $90 \mathrm{~A}$ arc current, the pressure and voltage are not strongly influenced by the flow rate of $\mathrm{O}_{2}$. This is opposed to $60 \mathrm{~A}$ arc current, for which there is an abrupt increase in working pressure with an increase in flow rate from $20 \mathrm{sccm}$ to $30 \mathrm{sccm}$ (constant pumping speed). This suggests a substantial change in the rate of gas consumption through reactions with the metal flux and absorption on the cathode and on the inner walls of the system. ${ }^{42}$ The increase therefore indicates a saturation in the gas being consumed by the metal flux, which is manifested as an increase in total pressure. This is consistent with the trend for $90 \mathrm{~A}$ arc current, for which the metal flux is higher, and consequently there is no such saturation. The abrupt increase in pressure can also be explained by an increase of the contamination rate of the cathode, which is known to promote a decrease in the material flux intensity. This also reduces the gas consumption rate and leads to an increase in the pressure.

The increase in the electrical potential on the cathodes in an $\mathrm{O}_{2}$ atmosphere, in particular for $60 \mathrm{~A}$ arc current (see Fig. 1), deserves some attention. As suggested for an $\mathrm{Al}$ cathode used in a $\mathrm{N}_{2}$ atmosphere, a lower electrical conductivity of AlN leads to arc dissipation, and provokes the ignition of arc spots. ${ }^{37,38}$ This can also be observed for thin $\mathrm{Al}$ oxide layers formed at a relatively low inflow rate of $\mathrm{O}_{2} .{ }^{33}$ However, as suggested in Ref. 33, a sufficient thickness of stable Al-rich oxide islands prohibits ignition of the arc spots on those surfaces, which reduces the active area of the cathode and increases the average 
resistivity of the cathode surface. Hence, the electrical potential may be increased to counteract for an increase in cathode area occupied by the oxides, and to compensate for the reduction in energy (current) provided to the area allowing arc ignition. This assumption is consistent with the model of arc plasma generation suggested by Lee and Greenwood ${ }^{52}$ and further developed by Beilis et al. ${ }^{53}$ In that model, a certain amount of energy has to be provided to the cathode surface for sustaining the arc discharge. ${ }^{53}$

For the present experimental setup, the oxide islands can be homogenously distributed over the cathode surface, since the absence of an external magnetic field does not induce frequently repeated arc tracks. It should also be noted that the arc discharge is glowing between at least two electrodes and oxides can also be formed on the anode (system walls or/and substrate). Electrons approaching an insulating layer at the anode create an electric field, which hampers them from reaching the anode. This can also contribute to the potential increase as shown in Fig. 1.

\subsection{Plasma characterization}

\subsubsection{Effect of $\mathrm{Si}$ in the cathode on plasma properties}

Depending on oxygen gas flow and arc current used, $\mathrm{Al}$ and $\mathrm{Cr}$ ions of charge states 1+, $2+$, and up to $3+$ could be detected in the plasma from the $\mathrm{Al}_{0.70} \mathrm{Cr}_{0.30}$ and $\mathrm{Al}_{0.70} \mathrm{Cr}_{0.25} \mathrm{Si}_{0.05}$ cathodes. Even at the base pressure of $5 \cdot 10^{-4} \mathrm{~Pa}$, that is without any oxygen introduced in the system, no significant intensity was recorded for charge states of $4+$ and higher. Figures 2 and 3 show IEDs measured with an arc current equal to $60 \mathrm{~A}$ at base pressure and for a flow rate of $30 \mathrm{sccm} \mathrm{O}_{2}$ in plasmas from the $\mathrm{Al}_{0.70} \mathrm{Cr}_{0.30}$ and $\mathrm{Al}_{0.70} \mathrm{Cr}_{0.25} \mathrm{Si}_{0.05}$ cathodes. At base pressure, the $\mathrm{Al}$ and $\mathrm{Cr}$ IEDs are independent on cathode composition, and the peak energies of all ions can be correlated through the "velocity rule", ${ }^{4}$ stating that all ion species generated in the arc spot have the same peak velocities (see Ref. 48, 54 for further details). 
At the flow rate of $30 \mathrm{sccm}$, the plasmas from both cathodes consist only of single charged ions with peak kinetic energies close to beginning of the energy axis (below $1 \mathrm{eV}$ ).

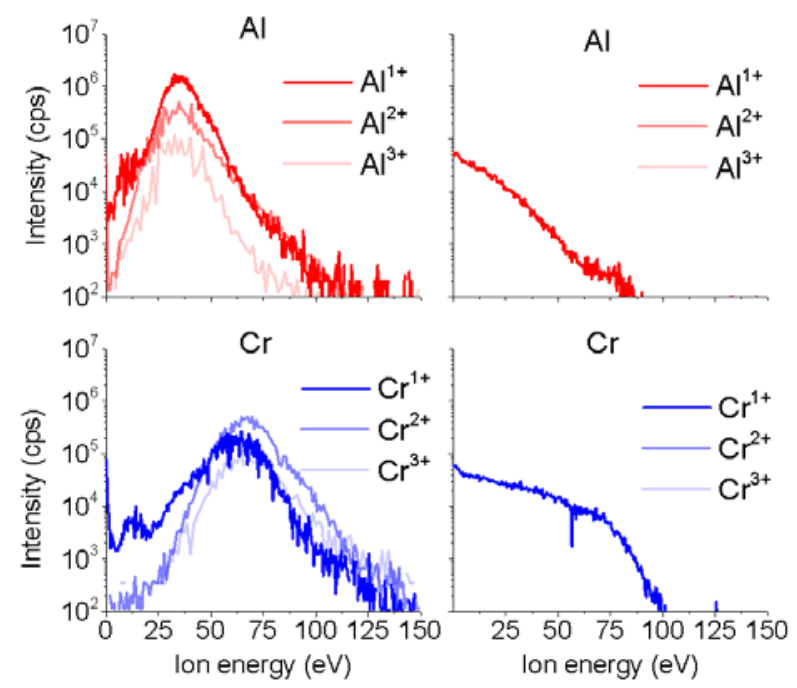

Figure 2 IEDs of $\mathrm{Al}$ (top) and $\mathrm{Cr}$ (bottom) ions at the base pressure $5 \cdot 10^{-4} \mathrm{~Pa}$ (left) and for a flow rate of $30 \mathrm{sccm}$ of $\mathrm{O}_{2}$ (right) in plasma from the $\mathrm{Al}_{0.70} \mathrm{Cr}_{0.30}$ cathode. Arc current $60 \mathrm{~A}$.
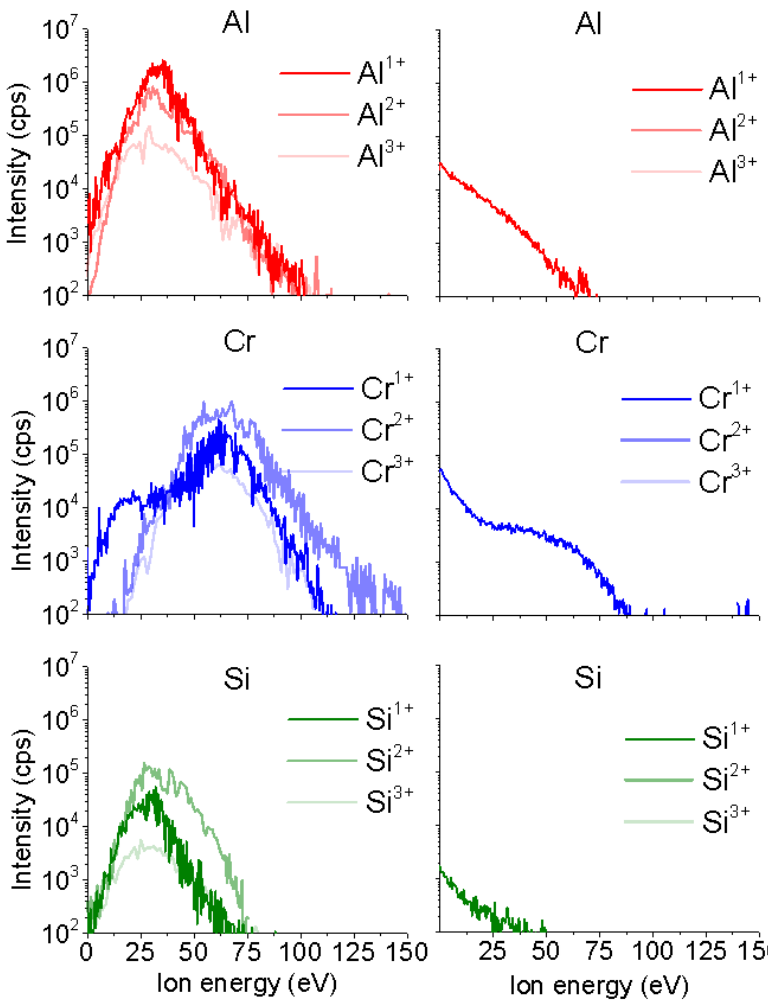

$\mathrm{Si}$

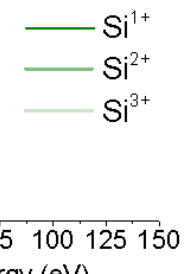

Figure 3 IEDs of $\mathrm{Al}$ (top), $\mathrm{Cr}$ (center) and $\mathrm{Si}$ (bottom) ions at the base pressure $5 \cdot 10^{-4} \mathrm{~Pa}$ (left) and for a flow rate of $30 \mathrm{sccm}$ of $\mathrm{O}_{2}$ (right) in plasma from the $\mathrm{Al}_{0.70} \mathrm{Cr}_{0.25} \mathrm{Si}_{0.05}$ cathode. Arc current 60 A. 


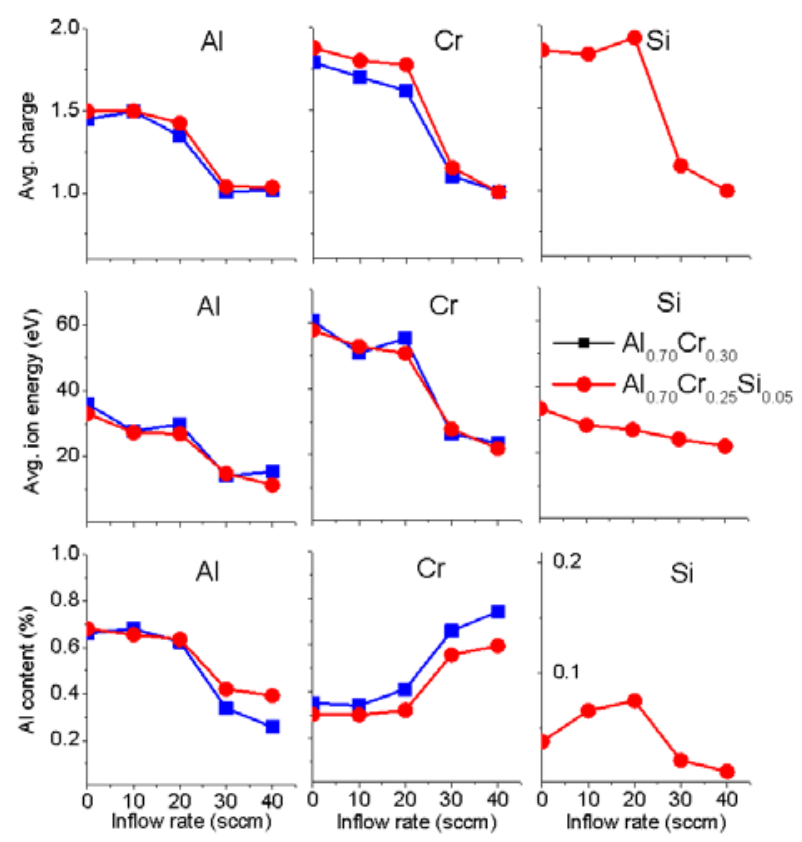

Figure 4 Properties of $\mathrm{Al}$ (left), $\mathrm{Cr}$ (center) and Si (right) ions as a function of flow rate of $\mathrm{O}_{2}$ from the $\mathrm{Al}_{0.70} \mathrm{Cr}_{0.30}$ and $\mathrm{Al}_{0.70} \mathrm{Cr}_{0.25} \mathrm{Si}_{0.05}$ cathodes. Arc current $60 \mathrm{~A}$.

In Figure 4, the average ion charge states, average ion energies and relative plasma ion content obtained at $60 \mathrm{~A}$ arc current are presented for increasing $\mathrm{O}_{2}$ flow rate. Figure 4 shows that an increase in the flow rate leads to a reduction in ion charge states and ion energies, consistent with previous work. ${ }^{55}$ However, the average charge states and the average ion energies from the different cathodes do not differ significantly (within the error bars), and considering the difference between the Cr content of the cathodes, the plasma composition curves also coincide within the limits of accuracy.

It is well known that collisions between neutral particles (gas) and plasma ions influence the plasma properties. Still, the correlated changes in the plasma properties (Fig. 4) and in the working pressure (Fig. 1) do not allow us to immediately distinguish between the influence of the gas on plasma generation at the cathode, on one hand, and on the plasma transportation on the other. At a high working pressure, the generated plasma close to the 
cathode could have relatively high ion energies and charge states, but have them strongly reduced at the analyzer, after travel in the gas. The relative increase in $\mathrm{Cr}$ content in the ionized part of the plasma, Figure 4 (middle), with an increase in flow rate can be explained by plasma-gas interaction, deviating from what to be expected of the plasma generated at the cathode. It is known that scattering upon collisions with gas particles is more pronounced for ions of lighter elements (Al and Si), compared to heavier ones $(\mathrm{Cr}){ }^{56}$ Thus a relative decrease is expected in the content of the lighter ions upon an increased pressure.

\subsubsection{Influence of arc current on plasma properties}

No influence of increased arc current, from 60 to 90 A, was detected for IEDs measured for both cathode compositions at base pressure (not shown here). Fig. 5 shows the IEDs measured for $90 \mathrm{~A}$ and a flow rate of $30 \mathrm{sccm} \mathrm{O}_{2}$ for both cathodes.

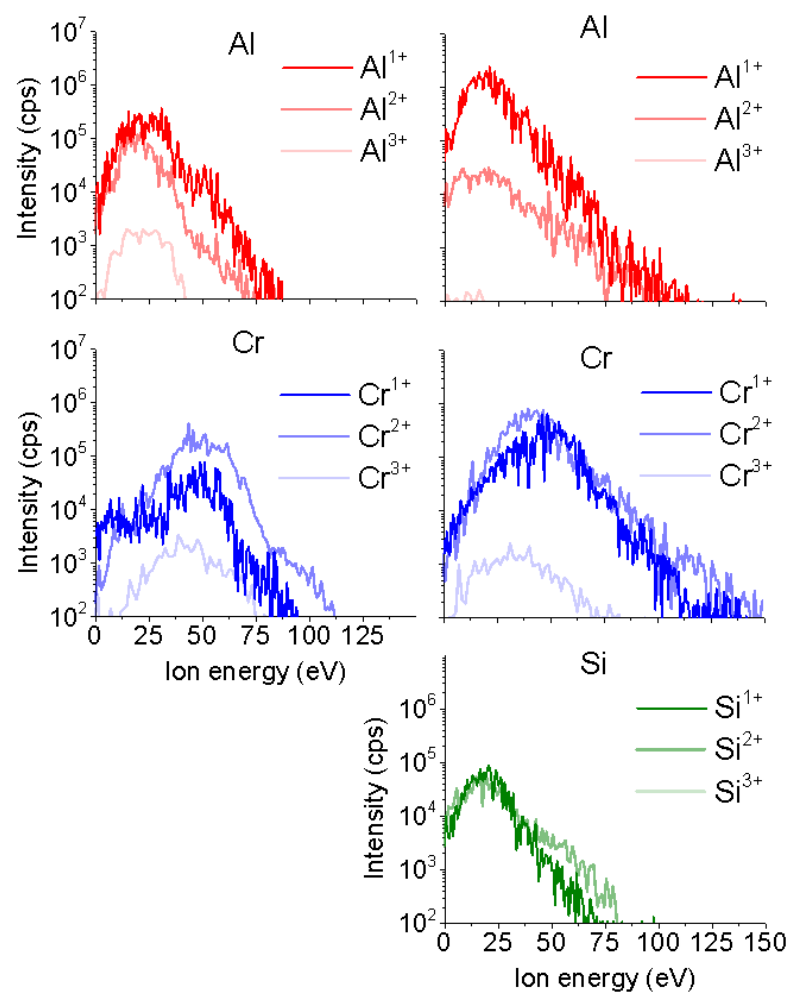

Figure 5 IEDs of Al (top), Cr (center) and Si (bottom) ions measured for an arc current of $90 \mathrm{~A}$ and with a flow rate of $30 \mathrm{sccm} \mathrm{O}_{2}$ for plasmas from $\mathrm{Al}_{0.70} \mathrm{Cr}_{0.30}$ (left) and $\mathrm{Al}_{0.70} \mathrm{Cr}_{0.25} \mathrm{Si}_{0.05}$ (right) cathodes. 
The IEDs presented in Fig. 2 (right) and 3 (right) were obtained for 60 A arc current. Comparing these IEDS with Fig. 5 (arc current 90 A), it is evident that the arc current influences the correlation between the flow rate and the plasma properties. For the same flow rates, the IEDs in Fig. 5 (90 A) are characterized by higher intensities, kinetic energies and charges of the ions. Furthermore, the peak energies in Fig. 5 are still correlated through the "velocity rule", 54 even at a flow rate of $30 \mathrm{sccm} \mathrm{O}$. This indicates that a substantial part of the ion flux has not been subject to plasma-gas interaction.

The arc current determines the intensity of the ion flux. ${ }^{1}$ Additionally, a higher arc current, and consequently a higher amount of energy provided to the cathode surface, can lead to an increase in generation of neutral vapor, ${ }^{1}$ as well as an increase in macroparticle generation through an increased number of arc spots. This is likely more pronounced in the metallic mode, though also expected in a reactive atmosphere. As a result, any increase in the arc current leads to an increase in intensity of the material flux from the cathode, which in turn influence the gas consumption and hence the total pressure.

Fig. 6 shows plots of the average ion charge, energy and plasma content vs oxygen flow for an arc current of $90 \mathrm{~A}$, to be compared to Fig. 4 in which the arc current is $60 \mathrm{~A}$. 


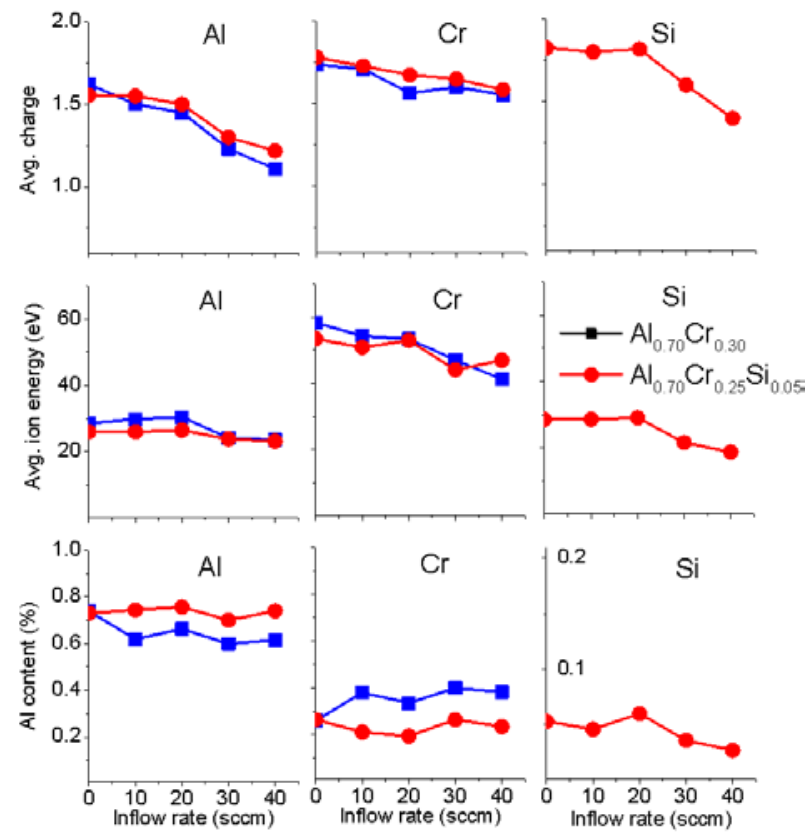

Figure 6 Properties of $\mathrm{Al}$ (left), $\mathrm{Cr}$ (center) and Si (right) ions as a function of flow rate of $\mathrm{O}_{2}$ from $\mathrm{Al}_{0.70} \mathrm{Cr}_{0.30}$ and $\mathrm{Al}_{0.70} \mathrm{Cr}_{0.25} \mathrm{Si}_{0.05}$ cathodes with arc current $90 \mathrm{~A}$.

Figure 6 shows that any differences in plasma properties between the different cathodes are within the error bars of 5-7\%. The effect of an increased flow rate on plasma properties is less pronounced compared to the plasma from $60 \mathrm{~A}$ arc current, though a significant reduction in ion charge states (primarily $\mathrm{Al}$ and $\mathrm{Si}$ ) and a slight reduction in ion energy (primarily for $\mathrm{Cr}$ ) is evident. The less pronounced effects from the flow of $\mathrm{O}_{2}$ at $90 \mathrm{~A}$ likely originates from the lower oxygen pressure due to not yet saturated gas consumption, see Fig. 1. The reduced charge states and energies with increasing flow rate may be explained by an increased cross section for collisions involving scattering as well as charge transfer. ${ }^{43,56}$

\subsubsection{Characterization of neutrals in the plasma}

It has previously been suggested that for reactive synthesis from an Al-Cr-Si cathode, eroded Si reacts with oxygen and forms volatile SiO species which are pumped out from the system and therefore not included in the resulting film. ${ }^{44}$ However, the films in the present 
work contain a significant amount of Si (see section 3.3 below). Still, a reduction of Si ions content in the plasma with an increase in the flow rate of $\mathrm{O}_{2}$ is detected, see Fig. 4 and Fig. 6. Using the "neutral mode" of the mass-energy analyzer ${ }^{51}$ which is based on internal ionization, strong signals at mass 28 and 44 amu are detected, corresponding to $\mathrm{Si}$ and $\mathrm{SiO}$ respectively, see Figure 7.

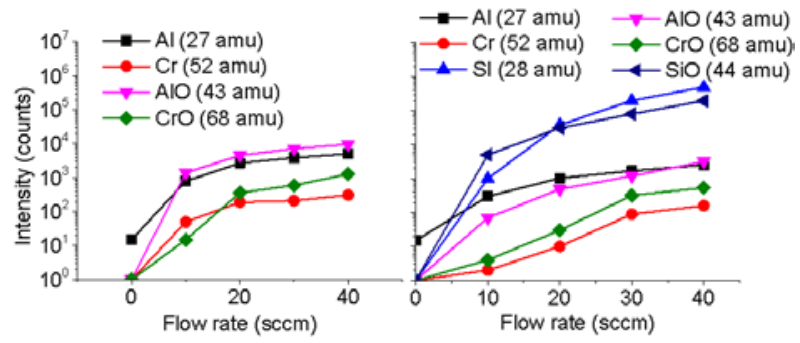

Figure 7 Intensities of detected neutral species of different atomic mass as function of the $\mathrm{O}_{2}$ flow rate measured in plasma from the $\mathrm{Al}_{0.70} \mathrm{Cr}_{0.30}$ (left) and $\mathrm{Al}_{0.70} \mathrm{Cr}_{0.25} \mathrm{Si}_{0.05}$ (right) and cathodes. The arc current is $60 \mathrm{~A}$.

This is consistent with the proposed formation of volatile silicon oxides during arcing, see Ref. 44. Considering the comparatively low Si content in the cathodes as well as in the coatings (see Section 3.3), it should be noted that the intensity of $\mathrm{SiO}$ and $\mathrm{Si}$ is significantly higher than all other neutral species detected, including $\mathrm{Al}$ and $\mathrm{Cr}$. However, it is not possible to quantitatively compare the intensities measured in "ion" and "neutral" mode of the mass-energy-analyzer. ${ }^{51}$ Therefore, the ratio between $\mathrm{Si}$ species in the ionized and neutral phase cannot be estimated. It has to be also noted that, as it is well known, some amount the oxides can be destroyed in time of the ionization process within the analyzer.

\subsection{Analysis of deposited coatings}

To assess the influence of the oxygen flow rate on the thin film deposition process, MgO substrates were coated for 15 minutes at flow rates of $0 \mathrm{sccm}, 20 \mathrm{sccm}$, and $40 \mathrm{sccm}$. 
Figure 8 presents SEM images of films deposited from the $\mathrm{Al}_{0.70} \mathrm{Cr}_{0.30}$ cathode at $60 \mathrm{~A}$ (top), and from the $\mathrm{Al}_{0.70} \mathrm{Cr}_{0.25} \mathrm{Si}_{0.05}$ cathode at $60 \mathrm{~A}$ (middle) and $90 \mathrm{~A}$ (bottom). At $90 \mathrm{~A}$, there is no observable difference between coatings from the different cathodes (data from the AlCr cathode not shown). Where possible, repeated EDX measurements were performed on the cathodes as well as the deposited films, see Fig. 8 with the film composition given in the top left of every picture. No discrepancy was observed between the cathode and the film composition, and no influence of the $\mathrm{O}_{2}$ flow rate on the Al-Cr-Si content was detected. The right-hand side pictures in the first two lines in Fig. 8 suggest formation of insulating oxides on the electrodes opposite to the cathode (mentioned in Section 3.1.), i.e. the anode/substrate.

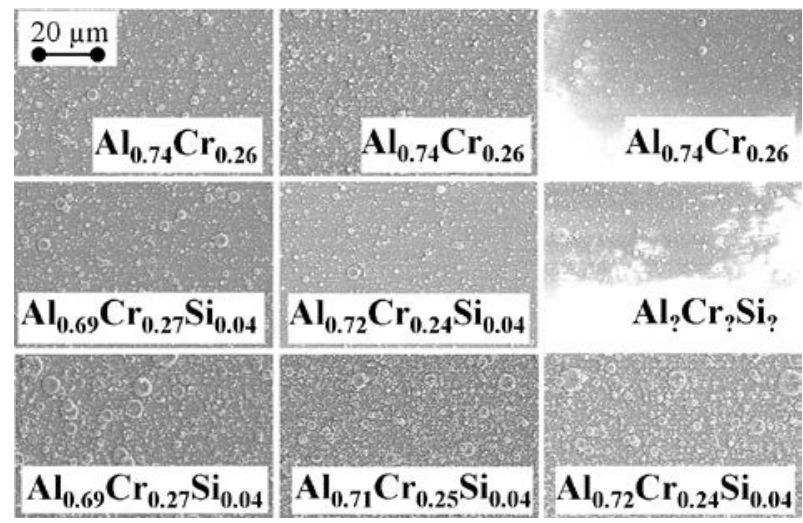

Figure $8 \mathrm{SEM}$ images of deposited films from $\mathrm{Al}_{0.70} \mathrm{Cr}_{0.30}$ (top, $60 \mathrm{~A}$ ) and $\mathrm{Al}_{0.70} \mathrm{Cr}_{0.25} \mathrm{Si}_{0.05}$ (center $60 \mathrm{~A}$ and bottom $90 \mathrm{~A}$ ). Flow rate of $\mathrm{O}_{2}$ is $0 \mathrm{sccm}$ (left), $20 \mathrm{sccm}$ (center) and 40 sccm (right).

Overall, there are macroparticles present at the surface of all deposited films. The most pronounced change is observed for the $60 \mathrm{~A}$ AlCrSi based coatings, with a reduction in the amount and size of the macroparticles when increasing the $\mathrm{O}_{2}$ flow to $20 \mathrm{sccm}$. In our previous work on Al-containing cathodes used in a reactive $\mathrm{N}_{2}$ atmosphere, a pronounced reduction in number of droplets was observed for an increase in the operational pressure, ${ }^{38}$ with only a few visible droplets at the highest pressure. We suggested that an increase in 
surface melting temperature and arc spot dissipation due to nitride contaminations, significantly decrease the intensity and size of macroparticles. ${ }^{38}$ In the present study, the reduction in number and size of macroparticles with an increase in pressure (top two rows in Fig. 8), suggests a similar influence from oxide contaminations, though not as pronounced as for the nitride case.

For the 90 A films, the similar appearance of the surfaces suggest that the cathode is in metallic mode throughout the range of $\mathrm{O}_{2}$ flow. In turn, a higher amount of droplets compared to the 60 A films is consistent with the previously shown increased droplet abundance from an increase in the arc current. ${ }^{1}$ As a result, possible requirements for a specific surface roughness of deposited films may be a limiting factor for variations in the arc current. It should be noted that the appearance of droplet content in the film may be influenced by film thickness and related overgrown particles. However, SEM-analysis of the cross section of the film supports the here presented trends.

Even though the correlation between macroparticle generation and visible macroparticles on the film surface is a first approximation only, ${ }^{57}$ trends in their formation can be identified. Figure 9 shows an example of EDX analysis of droplets at the film surface. The large droplet in the center of Fig. 9 evidently contains a higher amount of Si than the rest of the film, while the $\mathrm{Cr}$ signal for the same area is reduced. Still, not all droplets exhibit a higher Si content. Similar observation of Si rich droplets has been reported for Ti-Si cathodes. ${ }^{57,58}$ 


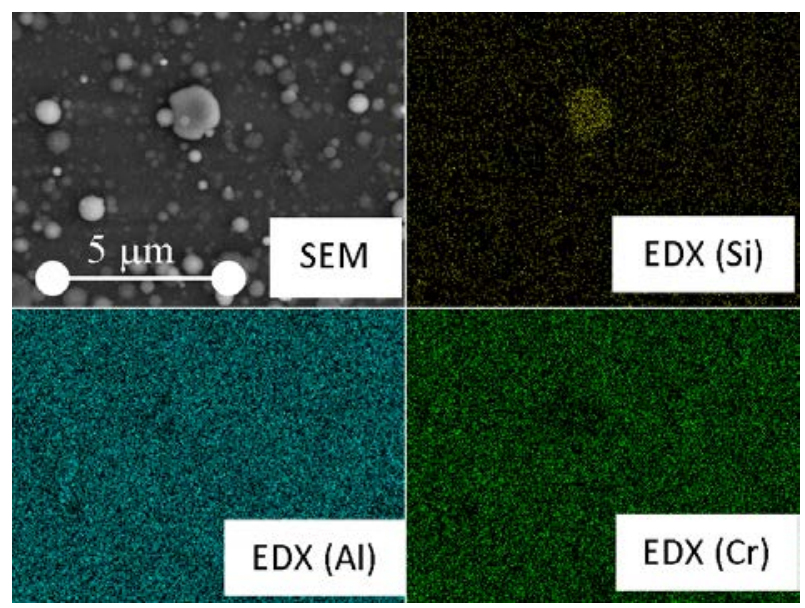

Figure 9 Illustration from SEM and EDX of frequently observed Si-rich droplets at the surface of films deposited at an $\mathrm{O}_{2}$ flow rate of $20 \mathrm{sccm}$ and an arc current of $60 \mathrm{~A}$.

To evaluate changes in the total material flux to the substrate, the film thickness was determined from the cross-section of the deposited films. Figure 10 shows the film thickness vs $\mathrm{O}_{2}$ flow rate for the here studied cathodes used at 60 and $90 \mathrm{~A}$.

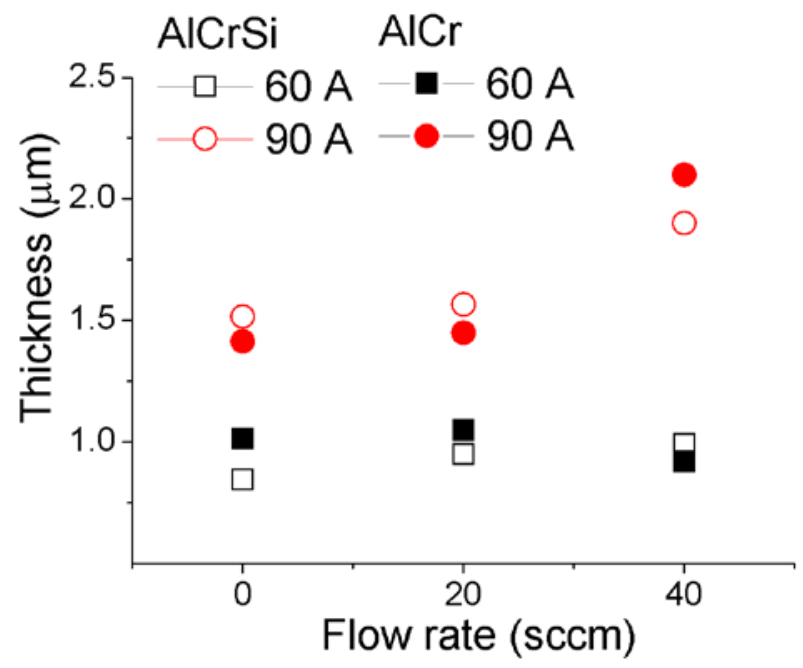

Figure 10 Films thickness as a function of $\mathrm{O}_{2}$ flow rate for $\mathrm{Al}_{0.70} \mathrm{Cr}_{0.30}$ and $\mathrm{Al}_{0.70} \mathrm{Cr}_{0.25} \mathrm{Si}_{0.05}$ cathodes used at 60 and $90 \mathrm{~A}$.

The films deposited at 90 A are significantly thicker compared to those from an arc current of $60 \mathrm{~A}$, which is consistent with the increase in material flux from the cathode with 
a higher arc current. Furthermore, the 60 A films show a thickness almost independent on the $\mathrm{O}_{2}$ flow rate. This, in turn, is consistent with the saturation of gas consumption suggested in connection to Figure 1. On the contrary, the increase in the thickness of the 90 A films indicates an increased amount of oxygen consumed in the film growth, which is consistent with a close to constant pressure, see Fig. 1. There is no significant difference between the films deposited from the cathodes with and without Si. Thus, any influence of the addition of Si on process behavior and plasma parameters is minor in comparison to the effect of arc current.

\subsection{Plasma generation in a reactive arc discharge}

A reactive gas can influence the plasma properties either at or close to the cathode surface where the plasma is generated, or through plasma-gas interaction during plasma transport towards a substrate. The plasma analysis presented in Section 3.2, indicates that all changes in the plasma properties (Fig. 4 and 6) for the arc current $60 \mathrm{~A}$, are generally caused by changes in the operational pressure (Fig. 1) and corresponding scattering and charge exchange collisions with the gas during transport. If so, a possible contamination of the cathode and formation of oxide islands prohibiting arc ignition mainly serve to reduce the operational area of the cathode surface, which may also change the intensity of the total material flux from the cathode. However, the increase in cathode potential (Fig. 1) shows that an influence of the oxygen atmosphere on the here studied arc discharge is more complex. To date, reports on the influence of a reactive gas on the arc discharge is commonly focused on investigation of the cathode surface. However, in the present work, we also discuss the possible change in conductivity of the surfaces opposite to the cathode the substrate/anode. As suggested in connection to Fig. 1, non-conducive layers on the anode may also be responsible for the increase in cathode potential (Fig. 1), and a change in 
electrical conductivity in the cathode - anode system can also be responsible for a change in properties of generated material flux. For an increased fundamental understanding of reactive arc processing, we therefore suggest that this somewhat neglected topic should be investigated together with more traditionally studied plasma generation, plasma transport, and resulting film formation.

\section{CONCLUSION}

DC arc plasma from $\mathrm{Al}_{0.7} \mathrm{Cr}_{0.3}$ and $\mathrm{Al}_{0.7} \mathrm{Cr}_{0.25} \mathrm{Si}_{0.05}$ compound cathodes (industrial size) has been characterized with respect to ion/neutral composition, ion charge state, and ion energy in a reactive $\mathrm{O}_{2}$ atmosphere at different $\mathrm{O}_{2}$ flow rates. The resulting coatings, from variations in $\mathrm{O}_{2}$ flow rate, arc current and cathode composition have also been evaluated.

When using the $\mathrm{Al}_{0.7} \mathrm{Cr}_{0.25} \mathrm{Si}_{0.05}$ cathode, Si-containing species are observed in all the three material fluxes: as neutrals and ionic species in the plasma, as well as in the droplets. These results corroborate the previously suggested presence of volatile SiO species in this type of discharge. However, $\mathrm{Si}$ is found in the coatings in approximate proportions as in the cathode, indicating that the loss of $\mathrm{Si}$ due to volatile $\mathrm{SiO}$ species is negligible.

The effect of adding $\mathrm{Si}$ in the Al-Cr cathode on the behavior of the reactive DC arc discharge and on the ion charge states, ion energies, droplet generation, as well as the resulting film formation was found negligible compared to the influence of arc current. The latter was identified as the most relevant parameter for tuning the properties of the reactive discharge and hence allow control of the coating process.

\section{ACKNOWLEDGEMENTS}

The Swedish Research Council (VR, grant number: 621-212-4368) is acknowledged for financial support for L.L's industry PhD studies with AB Sandvik Coromant. AB Sandvik 
Coromant is acknowledged for in kind contribution (cathodes). P.E. also acknowledges the Swedish Foundation for Strategic Research (SSF) through the Research Leaders 5 program. J.R. acknowledges financial support from the Knut and Alice Wallenberg (KAW) Foundation and the Swedish Government Strategic Research Area in Materials Science on Functional Materials at Linköping University (Faculty Grant SFO Mat LiU No. 2009 00971).

\section{REFERENCES}

1 A. Anders, "Cathodic Arcs. From Fractal Spots to Energetic Condensation," 1 ed. (Springer, New York, 2008).

2 D. Quinto, "Mechanical property and structure relationships in hard coatings for cutting tools.," Journal of Vacuum Science \& Technology A, vol. 3, no. 6, pp. 21492157, 1988.

3 S. Ruppi, "Advances in chemically vapour deposited wear resistant coatings," Journal De Physique, vol. 11, pp. 3847-3859, 2001.

$4 \quad$ K. D. Bouzakis, "Cutting with coated tools: Coating technologies, characterization methods and performance optimization," CIRP Annals - Manufacturing Technology, vol. 61, no. 2, pp. 703-723, 2012.

$5 \quad$ M. Fallqvist, M. Olsson and S. Ruppi, "Abrasive wear of texture-controlled CVD alpha-Al2O3 coatings.," Surface \& Coatings Technology, vol. 202, no. 4-5, pp. 837843, 2007.

$6 \quad$ S. Ruppi, "Enhanced performance of alpha-Al2O3 coatings by control of crystal orientation.," Surface \& Coatings Technology, vol. 17, no. 202, pp. 4257-4269, 2008.

7 J. Rosen, S. Mraz, U. Kreissig, D. Music and . J. M. Schneider, "Effect of Ion Energy on Structure and Composition of Cathodic Arc Deposited Alumina Thin Films," Plasma Chemistry and Plasma Processing, vol. 25, no. 4, pp. 303-317, 2005.

$8 \quad$ Y. Yamada-Takamura, F. Koch, H. Maier and H. Bolt, "Characterization of alphaphase aluminum oxide films deposited by filtered vacuum arc," Surface and Coatings Technology, vol. 142, pp. 260-264, 2001.

$9 \quad$ B. Tay, Z. Zhao and D. Chua, "Review of metal oxide films deposited by filtered cathodic vacuum arc technique," Materials Science and Engineering: R: Reports, vol. 52, no. 1-3, pp. 1-48, 2006.

R. Franz, P. Polcik and A. Anders, "Ion Charge State Distributions of Al and Cr in 
Cathodic Arc Plasmas from Composite Cathodes in Vacuum, Argon, Nitrogen, and Oxygen," IEEE Transactions on Plasma Science, vol. 41, no. 8, pp. 1929-1937, 2013.

K. Sarakinos, D. Music, F. Nahif, K. Jiang, A. Braun, C. Zilkens and J. Schneider, "Ionized physical vapor deposited Al2O3 films: Does subplantation favor formation of a-Al2O3?," Physica Status Solidi-Rapid Research Letters, vol. 4, no. 7, pp. 154-156, 2010.

E. Wallin, T. Selinder, M. Elfwing and U. Helmersson, "Synthesis of alpha-Al(2)O(3) thin films using reactive high-power impulse magnetron sputtering," Epl, vol. 82, no. 3, p. 36002, 2008.

T. Selinder, E. Coronel, E. Wallin and U. Helmersson, "alpha-Alumina coatings on WC/Co substrates by physical vapor deposition," International Journal of Refractory Metals \& Hard Materials, vol. 27, no. 2, pp. 507-512, 2009.

M. Sridharan, M. Sillassen, J. Bottiger, J. Chevallier and H. Birkedal, Surface and Coatings Technology,, vol. 202, no. 4-7, pp. 920-924, 2007.

O. Zywitzki, G. Hoetsch, F. Fietzke and K. Goedicke, Surf. Coat. Technol, vol. 82, p. 169, 1996.

J. Schneider, W. Sproul, A. Voevodin and A. Matthews, J. Vac. Sci. Technol. A, vol. 15, no. 3, p. 1084, 1997.

J. Schneider, W. Sproul and A. Matthews, Surf. Coat. Technol., vol. 94-95, p. 197, 1997.

P. Jin, G. Xu, M. Tazawa, K. Yoshimura, J. Alami and H. Helmersson, "Low temperature deposition of alpha-Al2O3 thin films by sputtering using a Cr2O3 template.," Journal of Vacuum Science \& Technology a-Vacuum Surfaces and Films, vol. 20, no. 6, pp. 2134-2136, 2002.

M. Pohler, R. Franz, J. Ramm, P. Polcik and C. Mitterer, "Seed layer stimulated growth of crystalline high $\mathrm{Al}$ containing $(\mathrm{Al}, \mathrm{Cr})(2) \mathrm{O}-3$ coatings deposited by cathodic arc evaporation.," Thin Solid Films, vol. 550, pp. 95-104, 2014.

P. Eklund, M. Sridharan, M. Sillassen and J. Bøttiger, "alpha-Cr2O3 template-texture effect on alpha-Al2O3 thin-film growth," Thin Solid Films, vol. 516, no. 21, pp. 74477450, 2008.

J. Andersson, Z. Czigány, P. Jin and U. Helmersson, "Microstructure of $\alpha$-alumina thin films deposited at low temperatures on chromia template layers," J.Vac.Sci.Technol. A, vol. 22, no. 117, 2004.

J. Ramm, M. Ante, T. Bachmann, B. Widrig, H. Brändle and M. Döbeli, "Pulse enhanced electron emission ( $\mathrm{P} 3 \mathrm{e}^{\mathrm{TM}}$ ) arc evaporation and the synthesis of wear resistant Al-Cr-O coatings in corundum structure," Surface \& Coatings Technology, vol. 202, pp. 876-883, 2007. and iron on the phase formation of arc evaporated Al-Cr-oxide coatings," Surface \& 
Coatings Technology, vol. 276, pp. 735-742, 2015.

C. Koller, J. Ramm, S. Kolozsva'ri, F. Munnik, J. Paulitsch and P. Mayrhofer, "Corundum-type Fe-doped cathodic arc evaporated Al-Cr-O coatings," Scripta Materialia, vol. 97, pp. 49-52, 2015.

M. Witthaut, R. Cremer, K. Reichert and D. Neuschutz, "Preparation of Cr2O3-Al2O3 solid solutions by reactive magnetron sputtering," Mikrochimica Acta, vol. 133, pp. 191-196, 2000.

K. Pedersen, J. Bøttiger, M. Sridharan, M. Sillassen and P. Eklund, "Texture and microstructure of $\mathrm{Cr} 2 \mathrm{O} 3$ and $(\mathrm{Cr}, \mathrm{Al}) 2 \mathrm{O} 3$ thin films deposited by reactive inductively coupled plasma magnetron sputtering," Thin Solid Films, vol. 518, no. 15, p. 42944298, 2010.

C. Koller, N. Koutná, J. Ramm, S. Kolozsvári, J. Paulitsch, D. Holec and P. Mayrhofer, "First principles studies on the impact of point defects on the phase stability of (AlxCr1-x)2O3 solid solutions," AIP Advances, vol. 6, no. 2, p. 025002, 2016.

E. Wallin and J. Andersson, "Effects of additives in alpha- and theta-alumina: an ab initio study," Journal of Physics-Condensed Matter, vol. 16, no. 49, pp. 8971-8980, 2004.

A. Khatibi, J. Palisaitis, C. Höglund, A. Eriksson, P. Persson, J. Jensen, J. Birch, P. Eklund and L. Hultman, "Face-centered cubic (A11-xCrx)2O3," Thin Solid Films, vol. 219, no. 8, pp. 2426-2429, 2011.

A. Khatibi, A. Genvad, E. Gothelid, J. Jensen, P. Eklund and L. Hultman, "Structural and mechanical properties of corundum and cubic $(\mathrm{AlxCr} 1-\mathrm{x}) 2+\mathrm{yO} 3-\mathrm{y}$ coatings grown by reactive cathodic arc evaporation in as-deposited and annealed states," Acta Materialia, vol. 61, no. 13, pp. 4811-4822, 2013.

B. Alling, A. Khatibi, S. Simak, P. Eklund and L. Hultman, "Theoretical investigation of cubic B1-like and corundum (Cr[sub 1 - x]Al[sub x])[sub 2]O[sub 3] solid solutions.," Journal of Vacuum Science \& Technology A: Vacuum, Surfaces, and Films, vol. 31, no. 3, pp. 030602-5, 2013.

D. Kurapov, "Non gamma - phase cubic AlCrO," 2010.

R. Franz, F. M. Martin, G. Hawranek and P. Polcik, "Erosion behaviour of composite Al-Cr cathodes in cathodic arc plasmas in inert and reactive atmospheres," Journal of Vacuum Science \& Technology A, vol. 34, no. 2, p. 021304, 2016.

M. Pohler, R. Franz, J. Ramm, P. Polcik and C. Mitterer, "Cathodic arc deposition of (Al,Cr)2O3: Macroparticles and cathode surface modifications," Surface \& Coatings Technology, vol. 206, pp. 1454-1460, 2011.

J. Ramm, A. Neels, B. Widrig, M. Döbeli, L. d. A. Vieira, A. Dommann and H. Rudigier, "Correlation between target surface and layer nucleation in the synthesis of $\mathrm{Al}-\mathrm{Cr}-\mathrm{O}$ coatings deposited by reactive cathodic arc evaporation," Surface and Coatings Technology, vol. 205, no. 5, pp. 1356-1361, 2010. 
A. Anders, B. Yotsombat and R. Binder, "Correlation between cathode properties, burning voltage, and plasma parameters of vacuum arcs," Journal of Applied Physics, vol. 89, no. 12, pp. 7764-7771, 2001.

I. Zhirkov, E. Oks and J. Rosen, "Effect of N2 and Ar gas on DC arc plasma generation and film composition from Ti-Al compound cathodes," Journal of Applied Physics, vol. 117, no. 21, p. 213301, 2015.

I. Zhirkov, . A. Petruhins and J. Rosen, "Effect of cathode composition and nitrogen pressure on macroparticle generation and type of arc discharge in a DC arc source with Ti-Al compound cathodes," Surface and Coatings Technology, vol. 281, pp. 20-26, 2015.

K. Jakubka and B. Juttner, "On the influence of surface conditions on initiation and spot types of unipolar arcs in a Tokamak," Journal of Nuclear Materials, vol. 102, pp. 259-266, 1981.

M. Bochkarev and A. Murzakaev, "Investigations of vacuum arc cathode spots with high temporal and spatial resolution," Discharges and Electrical Insulation in Vacuum, 1998. Proceedings ISDEIV. XVIIIth International Symposium on , vol. 1, pp. 244 251, 1998.

A. Rogozin and R. Fontana, "Reactive gas-controlled arc process," Discharges and Electrical Insulation in Vacuum, 1996. Proceedings. ISDEIV., XVIIth International Symposium on , vol. 2, pp. 957-961, 1996.

M. Kühn and F. Richter, "Characteristics in reactive arc evaporation," Surface and Coatings Technology, vol. 89, no. 1-2, pp. 16-23, 1997. Y. Raizer, Gas Discharge Physics (Original Russian edition), Moscow: Nauka, 1987.

J. Paulitsch, R. Rachbauer, J. Ramm, P. Polcik and P. H. Mayrhofer, "Influence of Si on the target oxide poisoning during reactive arc evaporation of (Al,Cr)2O3 coatings," Vacuum, vol. 100, pp. 29-32, 2014.

L. Landälv and a. e., "Influence of Si doping on process stability and coating properties during arc deposition of (Al, Cr)2O3," 2016.

G. Korb, "Process for the Manufacture of a target for cathodic sputtering". Patent US 4752335, 1987.

P. Wilhartitz, S. Schönauer and P. Polcik, "Method for producing an evaporation source". Patent EP1335995, 2003.

I. Zhirkov, A. Eriksson, A. Petruhins, M. Dahlqvist, A. Ingason and J. Rosen, "Effect of Ti-Al cathode composition on plasma generation and plasma transport in direct current vacuum arc," J. Appl. Phys., vol. 115, p. 123301, 2014.

I. Zhirkov, E. Oks and J. Rosen, "Experimentally established correlation between ion charge state distributions and kinetic ion energy distributions in a direct current vacuum arc discharge," Journal of Applied Physics, vol. 117, no. 9, p. 093301, 2015. 
A. Anders and E. Oks, "Charge-state-resolved ion energy distribution functions of cathodic vacuum arcs: A study involving the plasma potential and biased plasmas," $J$. Appl. Phys. 101, 043304 (2007).

Hiden Analytical Limited, "EQP/EQS Analyser Operator’s Manual," no. F Revision 1, 2009.

T. Lee and A. Greenwood, "Theory for the Cathode Mechanism in Metal Vapor Arcs," J. Appl. Phys., vol. 32, no. 5, pp. 916-923, 1961.

I. Beilis, "Cathode spot development on a bulk cathode in a vacuum arc," Ieee transactions on plasma science, vol. 41, no. 8, pp. 1979-1986, 2013.

I. Zhirkov, A. Eriksson and J. Rosen, "Ion velocities in direct current arc plasma generated from compound cathodes," J. Appl. Phys., vol. 114, 2013.

J. Rosén, A. Anders, S. Mráz, A. Atiser and S. Jochen, "Influence of argon and oxygen on charge-state-resolved ion energy distributions of filtered aluminum arcs," J. Appl. Phys. 99, 123303 (2006).

I. Beilis, A. Shashurin and R. L. Boxman, "Measurement of ion flux as a function of background gas pressure in a hot refractory anode vacuum arc," IEEE Transactions on Plasma Science, vol. 35, no. 4, pp. 973-979, 2007.

A. Eriksson, I. Zhirkov, M. Dahlqvist, J. Jensen, L. Hultman and J. Rosén, "Characterization of Plasma Chemistry and Ion Energy in Cathodic Arc Plasma from Ti-Si Cathodes of Different Composition," Journal of Applied Physics, 2013, 113( 16).

J. Zhu, M. Jõesaar, P. Polcik, J. Jensen, G. Greczynski, L. Hultman and M. Odén, "Influence of Ti-Si cathode grain size on the cathodic arc process and resulting $\mathrm{Ti}-\mathrm{Si}-$ N coatings," Surface and Coatings Technology, vol. 235, no. 25, pp. 637-647, 2013. 


\section{Figure captions}

Figure 1 Pressure in the chamber (top) and potential at the cathode (bottom) as function of flow rate of $\mathrm{O}_{2}$ in plasma from $\mathrm{Al}_{0.70} \mathrm{Cr}_{0.30}$ and $\mathrm{Al}_{0.70} \mathrm{Cr}_{0.25} \mathrm{Si}_{0.05}$ cathodes used at an arc current of $60 \mathrm{~A}$ (left) and $90 \mathrm{~A}$ (right).

Figure 2 IEDs of $\mathrm{Al}$ (top) and $\mathrm{Cr}$ (bottom) ions at the base pressure $5 \cdot 10^{-4} \mathrm{~Pa}$ (left) and for a flow rate of 30 sccm of $\mathrm{O}_{2}$ (right) in plasma from the $\mathrm{Al}_{0.70} \mathrm{Cr}_{0.30}$ cathode. Arc current $60 \mathrm{~A}$.

Figure 3 IEDs of $\mathrm{Al}$ (top), $\mathrm{Cr}$ (center) and $\mathrm{Si}$ (bottom) ions at the base pressure $5 \cdot 10^{-4} \mathrm{~Pa}$ (left) and for a flow rate of $30 \mathrm{sccm}$ of $\mathrm{O}_{2}$ (right) in plasma from the $\mathrm{Al}_{0.70} \mathrm{Cr}_{0.25} \mathrm{Si}_{0.05}$ cathode. Arc current 60 A.

Figure 4 Properties of $\mathrm{Al}$ (left), $\mathrm{Cr}$ (center) and $\mathrm{Si}$ (right) ions as a function of flow rate of $\mathrm{O}_{2}$ from the $\mathrm{Al}_{0.70} \mathrm{Cr}_{0.30}$ and $\mathrm{Al}_{0.70} \mathrm{Cr}_{0.25} \mathrm{Si}_{0.05}$ cathodes. Arc current $60 \mathrm{~A}$.

Figure 5 IEDs of Al (top), Cr (center) and Si (bottom) ions measured for an arc current of $90 \mathrm{~A}$ and with a flow rate of $30 \mathrm{sccm} \mathrm{O}_{2}$ for plasmas from $\mathrm{Al}_{0.70} \mathrm{Cr}_{0.30}$ (left) and $\mathrm{Al}_{0.70} \mathrm{Cr}_{0.25} \mathrm{Si}_{0.05}$ (right) cathodes.

Figure 6 Properties of $\mathrm{Al}$ (left), $\mathrm{Cr}$ (center) and Si (right) ions as a function of flow rate of $\mathrm{O}_{2}$ from $\mathrm{Al}_{0.70} \mathrm{Cr}_{0.30}$ and $\mathrm{Al}_{0.70} \mathrm{Cr}_{0.25} \mathrm{Si}_{0.05}$ cathodes with arc current $90 \mathrm{~A}$.

Figure 7 Intensities of detected neutral species of different atomic mass as function of the $\mathrm{O}_{2}$ flow rate measured in plasma from the $\mathrm{Al}_{0.70} \mathrm{Cr}_{0.30}$ (left) and $\mathrm{Al}_{0.70} \mathrm{Cr}_{0.25} \mathrm{Si}_{0.05}$ (right) and cathodes. The arc current is $60 \mathrm{~A}$. 
Figure $8 \mathrm{SEM}$ images of deposited films from $\mathrm{Al}_{0.70} \mathrm{Cr}_{0.30}$ (top, $60 \mathrm{~A}$ ) and $\mathrm{Al}_{0.70} \mathrm{Cr}_{0.25} \mathrm{Si}_{0.05}$ (center $60 \mathrm{~A}$ and bottom $90 \mathrm{~A}$ ). Flow rate of $\mathrm{O}_{2}$ is $0 \mathrm{sccm}$ (left), $20 \mathrm{sccm}$ (center) and 40 sccm (right).

Figure 9 Illustration from SEM and EDX of frequently observed Si-rich droplets at the surface of films deposited at an $\mathrm{O}_{2}$ flow rate of $20 \mathrm{sccm}$ and an arc current of $60 \mathrm{~A}$.

Figure 10 Films thickness as a function of $\mathrm{O}_{2}$ flow rate for $\mathrm{Al}_{0.70} \mathrm{Cr}_{0.30}$ and $\mathrm{Al}_{0.70} \mathrm{Cr}_{0.25} \mathrm{Si}_{0.05}$ cathodes used at 60 and $90 \mathrm{~A}$. 